\title{
524-NAD/NADH AS A MODEL REDOX SYSTEM: MECHANISM, MEDIATION, MODIFICATION BY THE ENVIRONMENT *
}

\author{
PHILIP J. ELVING, WILlIAM T. BRESNAHAN ${ }^{\star}$, JACQUES MOIROUX ${ }^{\star \star}$ and ZDENEK \\ SAMEC ${ }^{\dagger}$ \\ Department of Chemistry, University of Michigan, Ann Arbor, MI 48109 (U S A)
}

(Manuscript received March 10th 1982)

\section{SUMMARY}

The biologically important redox couple, $\beta$-nıcotinamide adenine dinucleotıde $/ 1,4, \beta$-dihydronicotinamide adenine dinucleotide, provides a grossly reversible prototype system for an overall electrode reaction consisting of two successive one-electron $\left(1 \mathrm{e}^{-}\right)$transfer steps coupled with (a) dimerization of an intermediate free radical product, (b) protonation-deprotonation of an intermediate product, (c) other chemical reactions, (d) adsorption of reactant, intermediate and product species, and (e) mediation by electrode surface species. Cathodic reduction of NAD ${ }^{+}$proceeds through two $1 \mathrm{e}^{-}$steps well separated in potential; protonation of the free radical produced on the first step occurs prior to the second electron-transfer; a first-order chemical reaction coupled to the latter may involve rearrangement of an initial dihydro product to 1,4-NADH (and some 1,6-NADH) In the apparently single stage $2 \mathrm{e}^{-}$anodic oxidation of NADH, the initial step is an irreversible heterogeneous electron transfer, which proceeds to at least some extent through mediator redox systems located close to the electrode surface; the resulting cation radical, NADH ${ }^{+\bullet}$, loses a proton (first order reaction) to form a neutral radical, NAD', which may participate in a second heterogeneous electron transfer (ECE mechanusm) or may react with NADH ${ }^{+*}$ (disproportionation mechanism DISP 1 or half-regeneration mechanism) to yield NAD ${ }^{+}$

\section{INTRODUCTION}

In numerous biological hydrogen-transfer reactions, $\beta$-nicotinamide adenine dinucleotide (NAD ${ }^{+}$; Fig. 1) functions as a coenzyme by accepting two electrons and a proton from a substrate $\left(\mathrm{SH}_{2}\right)$ in the presence of a suitable enzyme to form 1,4-dihydronicotinamide adenine dinucleotide (NADH; Fig. 1), the oxidized form of

\footnotetext{
- Invitea lecture read at the International Symposium on Bicelectrochemistry and Bioenergetics, June 28th-July 3rd 1981, Kiryat Anavim, Israel.

* Permanent address: Research Center, Hercules Inc., Wilmington, Delaware 19899, U S.A.

*** Permanent address: Ecole Normale Supèrieure de l'Enseignement Technique, 94230 Cachan, France.

t Permanent address: J. Heyrovsky Institute of Physical Chemistry and Electrochemistry, 10200 Prague 10, Czechoslovakia.
} 
the substrate (S) and a proton:

$\mathrm{SH}_{2}+\mathrm{NAD}^{+} \stackrel{\text { enzyme }}{\rightleftharpoons} \mathrm{S}+\mathrm{NADH}+\mathrm{H}^{+}$

The nicotinamide ring is the site of the reversible redox process (Fig. 1). In particular, $\mathrm{NAD}^{+}$serves as a coenzyme for pyridinoproteins (dehydrogenases) in the electron transport chain.

The electrochemical hehavior of the $\mathrm{NAD}^{+} / \mathrm{NADH}$ redox couple in aqueous media has received considerable atterition in recent years from the viewpoints of:

(a) using electrochemical approaches and methodology to model and study analogous biological phenomena,

(b) using the couple as an electrochemical regeneration step in cyclic redox processes involving chemical transformation and/or energy conversion, and

(c) analysis, e.g., in determining $\mathrm{NAD}^{+}, \mathrm{NADH}$ and compounds which react cnzymatically with $\mathrm{NAD}^{+}$or NADH (cf. Refs. 1-7 for summaries of such studies).

The present paper stresses the influence of experimental protocol on the results obtained on electrochemical studies of the NAD system in aqueous media, especially as related to the effects of adsorption of the various NAD species, the mediation role of adsorbed and other surface species on the electrode, and the time-scale of the particular experimental approach used.

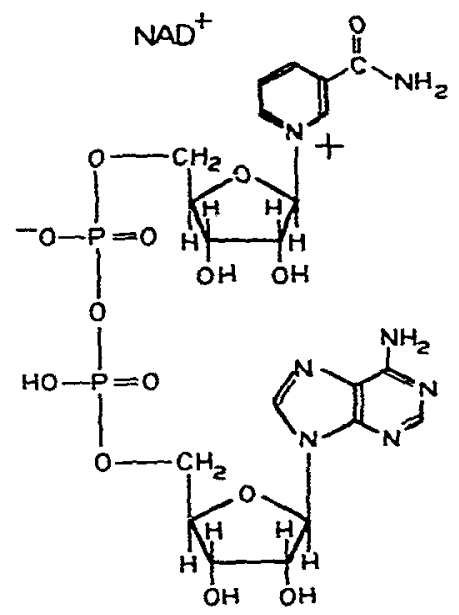<smiles>NC(=O)c1ccc[n+]([N+](=O)[O-])c1</smiles>

Fig 1. Nicotinamide adenine dinucleotide, $\mathrm{NAD}^{+}$, in its enzymatically active $\beta$ form and its biologically reduced form, I,4NADH. ADPR is adenosine diphosphoribose. 
Due to space limitation, experimental evidence and logical argument, which led to the mechanistic steps postulated, have been largely omitted; similarly, no attempts have been made to assign priorities or at thoroughness of coverage.

THE ELECTROCHEMICAL NAD SYSTEM

The basic pattern seen for electrochemical reduction of $\mathrm{NAD}^{+}$and electrochemical oxidation of NADH and of the NAD dimer is summarized in Fig. 2. The one-electron $\left(1 \mathrm{e}^{-}\right.$) cathodic wave at ca. $-1 \mathrm{~V}$ represents reduction of $\mathrm{NAD}^{+}$to the free radical (NAD), which dimerizes to (NAD) $)_{2}$ and which can be reduced ( $1 \mathrm{e}^{-}$ process) at ca. $-1.6 \mathrm{~V}$ to $\mathrm{NADH}$. The dimer is oxidized to $\mathrm{NAD}^{+}$at ca. $-0.4 \mathrm{~V}$. The difference in ease of the $2 \mathrm{e}^{-}$oxidation of $\mathrm{NADH}$ to $\mathrm{NAD}^{+}$at different electrode materials is due to the subsequently discussed mediation effects. (All potentials cited are versus the aqueous saturated calomel electrode.)

The dimer can undergo a pioton-assisted disproportionation to $\mathrm{NAD}^{+}$and NADH [8], which is at least formally analogous to the disproportionation of a semiquinone:

$\mathrm{QH}-\mathrm{QH} \rightarrow \mathrm{Q}+\mathrm{QH}_{2}$

$(\mathrm{NAD})_{2}+\mathrm{H}^{+} \rightarrow \mathrm{NAD}^{+}+\mathrm{NADH}$

Thus, the NAD ${ }^{+} / \mathrm{NADH}$ redox couple provides a grossly reversible electrochemical prototype system for an overall electrode reaction consisting of two successive 1 $\mathrm{e}^{-}$transfer steps coupled with:

(a) dimerization of an intermediate free radical product,

(b) protonation-deprotonation of an intermediate product,

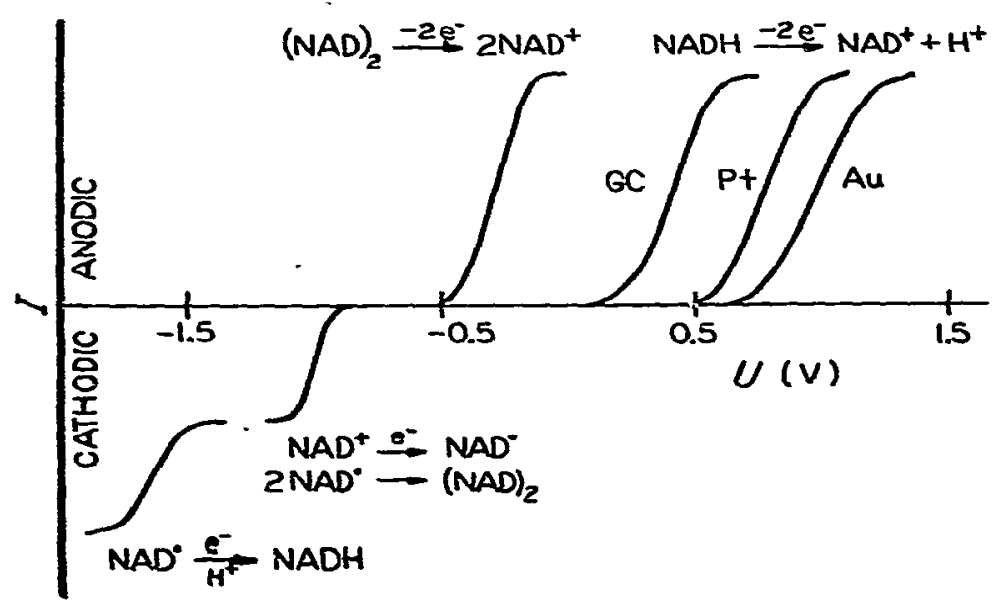

Fig. 2. Composite representation of the voltammetric waves for the NAD system. The calculated formal potential, $U_{c}^{0}$, for the half-reaction, $\mathrm{NAD}^{+}+\mathrm{H}^{+}+2 \mathrm{e}^{-}=\mathrm{NADH}$, at $\mathrm{pH} 7$ and $25^{\circ} \mathrm{C}$ is $-0.557 \mathrm{~V}$. Potentials are versus s.c.e. 
(c) other chemical reactions,

(d) adsorption of reactant, intermediate and product species, and

(e) mediation by electrode surface species.

Cathodic reduction of $\mathrm{NAD}^{+}$

In aqueous solution, 40 to $60 \%$ of the $\mathrm{NAD}^{+}$exists in a folded conformation, which brings the nicotinamide and adenine rings together [9-11], e.g., a fold involving the pyrophosphate group as a hinge (cf. Fig. 1). The NAD* free radical also has a folded configuration in aqueous solution; however, it is unfolded when attached to an enzyme.

As was noted (Fig. 2), the cathodic reduction of $\mathrm{NAD}^{+}$to $\mathrm{NADH}$ at mercury electrodes proceeds through two $1 \mathrm{e}^{-}$steps well separated in potential (Fig. 3).

Wave $I$ process. The $\mathrm{pH}$-independence of the initial $1 \mathrm{e}^{-}$reduction of $\mathrm{NAD}^{+}$is associated with the reduction of a cationic species. The faradaic process is accompanied by possible adsorption of $\mathrm{NAD}^{+}$, free radical $\mathrm{NAD}^{-}$, dimeric (NAD) 2 and background electrolyte cation.

Through variation in the ionic strength and surface activity of the background electrolyte, it is possible to formulate detailed mechanistic pathways involving the relative participation of adsorbed and dissolved species in the initial $1 \mathrm{e}^{-}$reduction of $\mathrm{NAD}^{+}$to NAD', including, for example, the facts that the orientation of adsorbed $\mathrm{NAD}^{+}$varies with the nature of the electrode surface and that the kinetics of the accompanying free radical dimerization can be validly determined only under conditions involving solution composition, initial potential and potential scan rate,

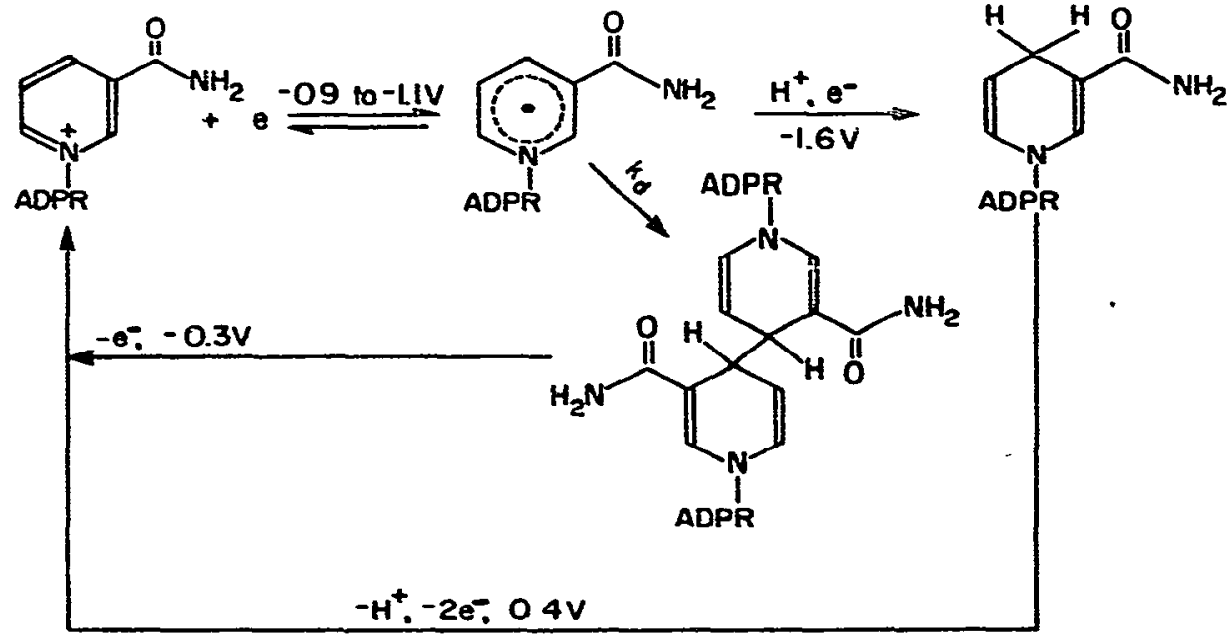

Fig 3 Summary electrochemical pattern for the NAD system (cf. Figs. 1 and 2). Potentiais are cersus s.ce 


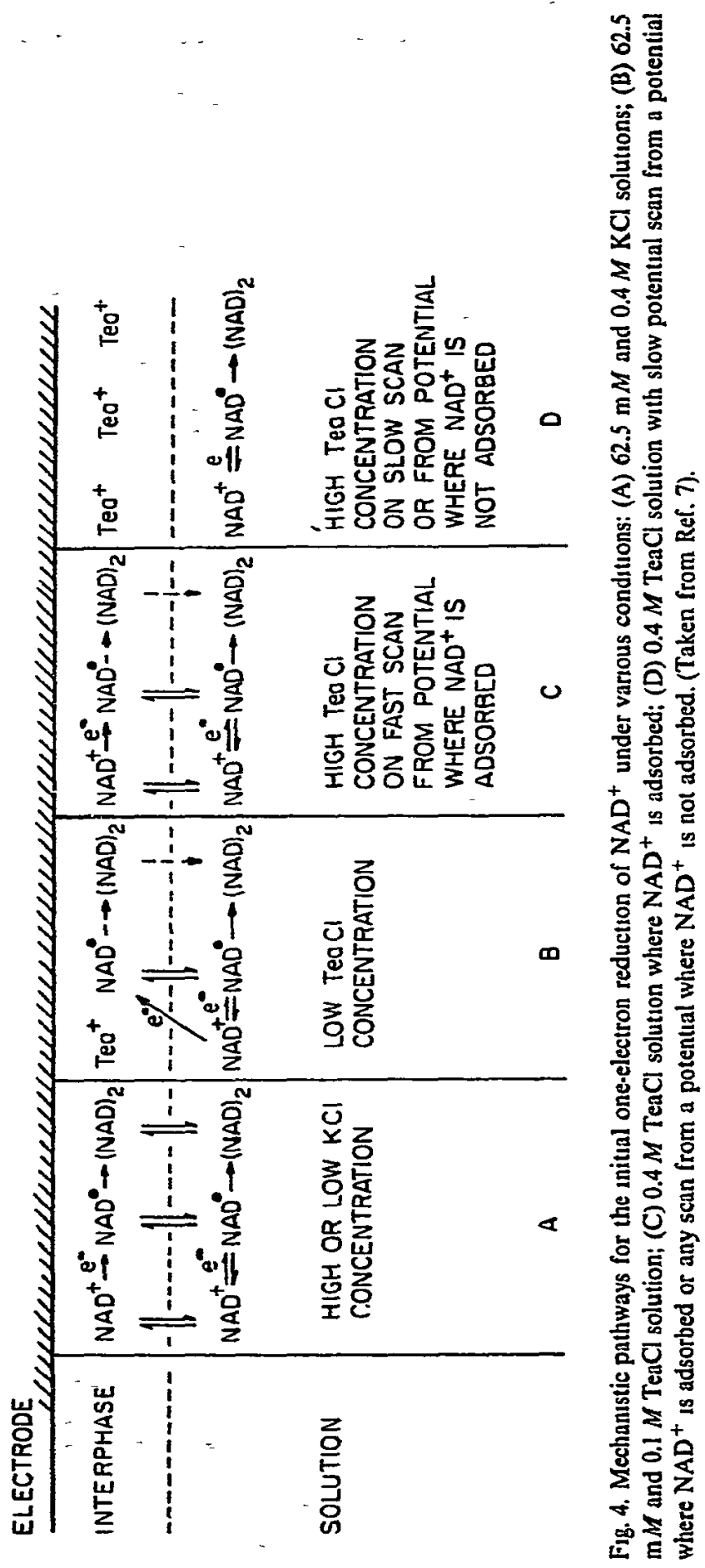


for which $\mathrm{NAD}^{+}, \mathrm{NAD}^{\circ}$ and (NAD) ${ }_{2}$ are not adsorbed at the interface.

In essence, the mechanisms operative for reduction of $\mathrm{NAD}^{+}$to $\mathrm{NAD}^{-}$are dependent on:

(a) competing adsorption.

(b) time-scale of the experiment,

(c) initial state of the electrode surface, and

(d) background solution ionic strength and surface activity (Fig. 4) [7]. The initial electrode surface state is controlled by the initial potential of the experiment. The nature of the buffer is not expected to affect significantly the pathways because the initial $1 \mathrm{e}^{-}$reduction is not sensitive to $\mathrm{pH}$ above $\mathrm{pH} 5[12,13]$, and Tris and carbonate are not measurably surface-active in the solutions used in deducing Fig. 4.

A rapid potential sweep from a potential, where $\mathrm{NAD}^{+}$is adsorbed, produces an adsorption-controlled current (Fig. 4, panel A); a slow sweep from the same potential produces a diffusion-controlled current.

In the presence of low surfactant concentrations (panel B), two processes are seen on both slow and fast time scales; as $\mathrm{NAD}^{+}$diffuses to the electrode, it is reduced to both soluble and adsorbed products. Dimerization of $\mathrm{NAD}^{-}$in the interphase would be followed by rapid desorption (the dashed arrow indicates the effective absence of dimer in the interphase).

At high surfactant concentration, the situation is dependent on both initial potential and scan rate. On rapid scan, $\mathrm{NAD}^{+}$, if initially adsorbed (panel $\mathrm{C}$ ), is reduced under both diffusion and adsorption control.

On slow scan or on rapid scan from a potential at which $\mathrm{NAD}^{+}$is not adsorbed (panel D), only diffusion-controlled reduction is seen.

An important implication of these results is that the dimenzation rate for NAD can be validly determined only under the conditions of panel $D$ of Fig. 4. Under these conditions, $k_{\mathrm{d}}$ is $2.7 \times 10^{6} \mathrm{M}^{-1} \mathrm{~s}^{-1}$; under the same conditions, the heterogeneous charge-transfer rate constant for the $1 \mathrm{e}^{-}$reduction of $\mathrm{NAD}^{+}$is ca. $0.1 \mathrm{~cm}$ $\mathrm{s}^{-1}[7]$.

Wave 11 process. The non-reduction of $\mathrm{NAD}^{\circ}$ in aprotic media, i.e., only $\mathrm{NAD}^{+}$ wave I appears, indicates the need for protonation prior to or concurrent with charge transfer [14].

The $\mathrm{pH}$ range, over which $\mathrm{NAD}^{+}$wave II can be examined in aqueous media, is effectively restricted to $\mathrm{pH} 7$ to 10 by background discharge and compound hydrolysis. Within this range, the observed $\Delta U / \Delta(\mathrm{pH})$ of ca. $20 \mathrm{mV}$, as compared to a theoretical value of $59 \mathrm{mV}$, indicates that the free proton donor, $\mathrm{H}_{3} \mathrm{O}^{+}$, is not the only significant contributor to the formation of reducible free radical species; solvent water and/or buffer constituent must also serve as proton donors. The situation is largely related to the very weak base character of NAD;, e.g., the free radical is not protonated at $\mathrm{pH} 0.4$ [15]. Based on the results indicated and other data, the reaction sequence for wave II is likely of the following nature:

$$
\mathrm{NAD}^{-}+\mathrm{HX}^{\stackrel{\ell_{p}}{\rightleftharpoons}} \mathrm{NAD}^{-}-\mathrm{H}-\mathrm{X} \underset{k_{s}}{\stackrel{\mathrm{e}^{-}}{\rightarrow}}\left[\mathrm{NADH}-\mathrm{X}^{-}\right] \underset{k_{r}}{\stackrel{-\mathrm{X}^{-}}{\rightarrow}} \mathrm{NADH}
$$




\section{TABLE 1}

Adsorption of $\mathrm{NAD}^{+}$at solutionjelectrode interfaces

1 Calculated minimum areas occupied per adsorbed $\mathrm{NAD}^{+}$molecule

1 Extended configuration: $190 \ddot{\mathrm{A}}^{2}$

2 Folded configuration, parallel to electrode surface: $125 \dot{A}^{2}$

3 Folded configuration, perpendicular to electrode surface: $85 \dot{A}^{2}$

II Experimentally determined areas for $\mathrm{NAD}^{+}$covered electrodes

1 Mercury: $130 \dot{A}^{2}$

2 Glassy carbon: $90 \pm 10 \dot{A}^{2}$

3 Pyrolytic graphite: $110 \pm 10 \dot{\mathrm{A}}^{2}$

4 Platinum: negligible adsorption

where $\mathrm{HX}$ is a proton donor. The last step, which is a rapid first-order chemical reaction, may involve rearrangement of an initial dihydro product to 1,4-NADH (and some 1,6-NADH). Rearrangements, subsequent to the $2 \mathrm{e}^{-}$electrochemical reduction of $\mathrm{NAD}^{+}$analogues, have been reported [16].

The effect of $\mathrm{HX}$ is illustrated by the pronounced increase in ease of NAD reduction when $\mathrm{K}^{+}$in the background electrolyte is replaced by $\mathrm{NH}_{4}^{+}$at $\mathrm{pH} 9$ [17]. Such behavior is attributable

(a) to the positive charge in the area of the nicotinamide moiety for the NAD $\mathrm{NH}_{4}^{+}$adduct but not for $\mathrm{NAD}^{-} \cdot \mathrm{H}_{2} \mathrm{O}$ and

(b) to $\mathrm{NH}_{4}^{+}$( $\mathrm{pK}$ a 9.2) being a stronger acid than $\mathrm{H}_{2} \mathrm{O}$ ( $\mathrm{p} K_{a}$ 15.7); this would favor the last dissociation step of equation 4, shifting the whole equilibrium to the right. In general, addition at constant $\mathrm{pH}$ of a Bronsted or Lewis acid stronger than water facilitates the reduction, i.e., increases the charge-transfer rate.

Adsorption of $\mathrm{NAD}^{+}$. Currently, considerable attention is being given to the orientation of biological molecules at solution/electrode interfaces, e.g., studies of the nucleic acid components [18]. Similarly, NAD studies have emphasized the importance of electrode nature and of temporal phenomena on the orientation of adsorbates.

The upper portion of Table 1 lists the minimum areas theoretically occupied by three different configurations of adsorbate $\mathrm{NAD}^{+}$, as deduced from projections of CPK space-filling models [19] of $\mathrm{NAD}^{+}$for monolayer coverage. The lower half of Table 1 lists the experimentally determined area per $\mathrm{NAD}^{+}$molecule on commonly used electrodes when the electrode surface is effectively saturated with $\mathrm{NAD}^{+}$.

Thus, the area occupied per $\mathrm{NAD}^{+}$molecule on a mercury electrode, as determined by surface excess measurements, decreases with increasing $\mathrm{NAD}^{+}$concentration to a limiting value of $130 \AA^{2}$. Based on this value and other data, our working model for the orientation of $\mathrm{NAD}^{+}$adsorbed at a solution|mercury interface involves a folded configuration of the coenzyme with the nicotinamide and adenine rings parallel and close to each other and with the adenine ring (at least initially) flat on the electrode surface. This model evokes the concept of electron 
transfer from electrode through the adenine ring to the nicotinamide ring- The possibility of adenine serving as a mediator for nicotinamide reduction is supported by evidence based on pulse radiolysis and fluorescence as well as electrochemistry [20.21].

The perpendicular orientation of $\mathrm{NAD}^{+}$on a glassy carbon surface, based on the area determined by the charge consumed on application of a potential sweep to a covered electrode, is in agreement with a proposed adsorption sequence for NAD ${ }^{+}$ produced at a glassy carbon surface by anodic NADH oxidation [22]. An initial rapid sorption of $\mathrm{NAD}^{+}$to a flat, i.e., parallel, orientation, which is the cause of the prewave seen on NADH oxidation [22-24], is followed by a relatively slower reorientation to a more tightly bound layer resulting from the perpendicular orientation, in which stacking association between adenine and nicotinamide moieties in adjacent folded molecules is favored.

Since the pyrolytic graphite surface consists of more or less flat oriented hexagonal rings, parallel orientation of folded $\mathrm{NAD}^{+}$may be somewhat favored with reorientation to the perpendicular state being slowed down or hindered.

As noted, $\mathrm{NAD}^{+}$is not appreciably adsorbed at a platinum surface from aqueous solution.

\section{Anodic oxidation of $N A D H$}

The anodic oxidation of NADH has been examined at glassy carbon (GC), pyrolytic graphite (PG), platinum (Pt) and gold ( $\mathrm{Au}$ ) electrodes.

Due to the dependence of interfacial adsorption on the applied potential and on time, the temporal response characteristics of the experimental arrangement are as important as they were for the $\mathrm{NAD}^{+}$reduction. An added experimental factor, resulting from the use of solid electrodes, involves the exact nature of the electrode material, its configuration and its previous history insofar as these affect the nature of the electrode surface.

For example, at GC electrodes. a prewave appears on NADH oxidation due to the weak or negligible adsorption of NADH and the strong adsorption of $\mathrm{NAD}^{+}$, i e.,

$\mathrm{N} . \mathrm{ADH} \underset{-\mathrm{H}^{+}}{\stackrel{-2 e^{-}}{\rightarrow}} \mathrm{NAD}^{+} \rightarrow \mathrm{NAD}_{a d s}^{+}$

The normal NADHi anodic wave appears at concentrations of NADH exceeding ca. $0.1 \mathrm{~m} M$. The prewave can be eliminated by first saturating the electrode surface with $\mathrm{NAD}^{+}$, e.g., by adding $\mathrm{NAD}^{+}$to the solution and waiting or by electrolytically generating $\mathrm{NAD}^{+}[22,24]$.

Mechanisms of NADH oxıdation. Although it is at times difficult to oxidize NADH cleanly at solid electrodes, it is well established that it undergoes an apparently single-step $2 \mathrm{e}^{-}$oxidation to enzymatically active $\mathrm{NAD}^{+}[25-29]$ :

$\mathrm{NADH} \rightarrow \mathrm{NAD}^{+}+\mathrm{H}^{+}+2 \mathrm{e}^{-}$ 
Thus, in both aqueous and nonaqueous media, NADH shows a single diffusion-controlled cyclic voltammetric anodic peak; scan reversal produces a cathodic peak due to $\mathrm{NAD}^{+-}$at ca. $-1.5 \mathrm{~V}$ more negative potential. A key detail in the NADH oxidation pattern is the deprotonation step and its relation to the initial potentialdetermining electron-transfer step.

In general, the mechanistic path operative in the NADH oxidation depends on the nature of the electrode surface. The irreversibility of the first electron transfer is likely to be the major cause of the overpotential required as compared to the enzymatically determined oxidation potential (Fig. 2).

Mechanism for occupied adsorption sites. Figure 5 summarizes the mechanistic path when adsorption sites are occupied by strongly adsorbed $\mathrm{NAD}^{+}$(supplementary equations are given in Ref. 6).

The large activation energy or overpotential required for the initial electron loss to form the cation radical,

$\mathrm{NADH} \stackrel{U_{1}(\beta)}{\rightarrow} \mathrm{NADH}^{+\cdot}+\mathrm{e}^{-}$

is apparently due to the need for a preliminary rearrangement. The possible involvement of the amide group in a transitory stage of the oxidation process is suggested by the fact that only 1,4-NADH is enzymatically active. The involvement of the enol form as the electrochemically oxidizable species is supported by the fact that orthoquinones covalently bound to carbon electrodes catalyze the electrochemical oxidation of NADH as well as that of an ene-diol such as ascorbic acid [30].

The second step is a first-order deprotonation to the neutral radical $\mathrm{NAD}^{\circ}$; this reaction would be practically irreversible since the neutral radical. due to its aromatic ring, is probably far more stable than the cation radical (cf. previous reference to $\mathrm{NAD}$ protonation). The absence of an $U_{1 / 2}$ shift with $\mathrm{pH}$ for $\mathrm{NAD}^{+}$ wave I and only a small $\mathrm{pH}$-dependence for $\mathrm{NAD}^{+}$wave II show that the protonation of $\mathrm{NAD}^{\circ}$ is neither easy nor rapid.

The third step can follow two different paths. One involves a second heterogeneous electron transfer,

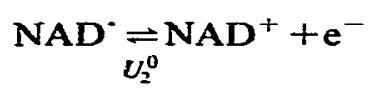

which is reversible. Although NAD dimerizes very rapidly, the dimer is electrochemically oxidized at ca. $-0.4 \mathrm{~V}$ (Fig. 2) and, consequently, would be oxidized to NAD ${ }^{+}$ at the potential of ca. $0.5 \mathrm{~V}$ required for the first step. This sequence of steps would constitute an overall ECE process (Fig. 5).

The alternate path for the NAD ${ }^{\circ}$ oxidation or second electron transfer involves a disproportionation reaction between the neutral and cation radicals $\mathrm{NAD}^{\circ}$ and $\mathrm{NADH}^{+*}$; such a half-regeneration reaction is probably more rapid than the preceding deprotonation which remains the rate-determining step. The resulting mechanism has been termed an DISP 1 mechanism [31,32].

The margin of error in determining $k$ for an ECE mechanism on the one hand 


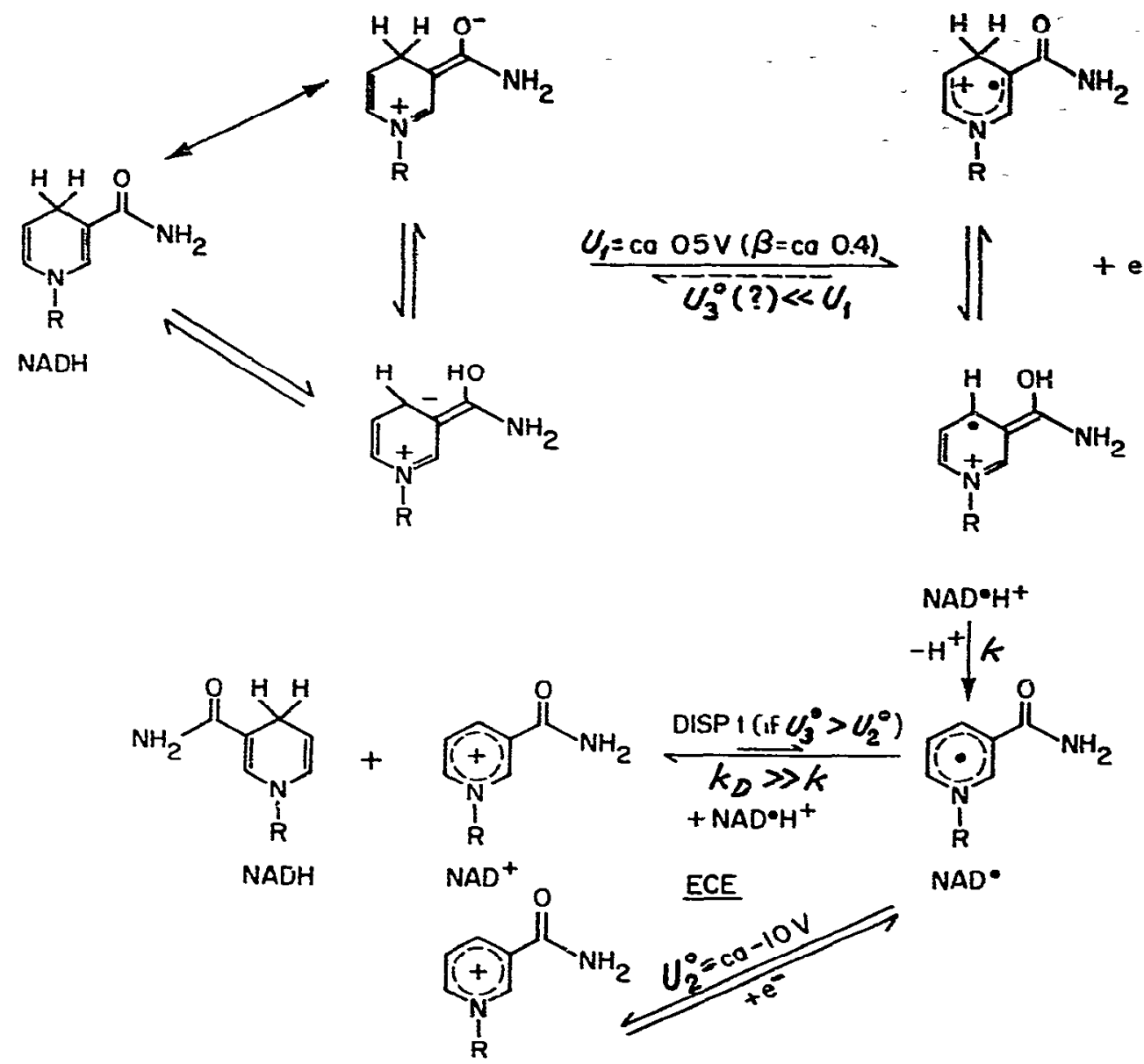

Fig 5 Reaction path for the electrochemical oxidation of NADH: $U_{1}$ is the oxidation potential of NADH to $\mathrm{NADH}^{+-}$(equation 7); $U_{2}^{0}$ is the reversible potential for the $\mathrm{NAD}^{+} / \mathrm{NAD}^{\circ}$ couple (equation 8); $U_{3}^{0}$ is the reversible potentual for the $\mathrm{NADH}^{+\cdot}$ couple, $k$ is the deprotonation rate constant (equation 9 ); $k_{D}$ is a disproportionation rate constant $\mathrm{NAD}^{+}, \mathrm{NAD}^{-}$and $\mathrm{NADH}^{+\cdot}$ can exist in resonant forms. (Taken from Ref. 6) Potentials are versus $s c e$.

and for a DISP 1 mechanism on the other hand does not allow distinguishing between the two [6].

Values of the deprotonation rate constant,

$\mathrm{NADH}^{+\cdot} \stackrel{k}{\rightarrow} \mathrm{NAD}^{\cdot}+\mathrm{H}^{+}$

are summarized in Table 2. The temperature variation of $k$ at the GC electrode at pH 7.1 confirms the presence of a chemical limiting step (activation energy $=c a .60$ $\left.\mathrm{kJ} \mathrm{mol}{ }^{-1}\right)$. The magnitude of $k$ correlates with the extent of coverage of the electroxle by adsorbed NAD ${ }^{+}$(cf. Table 1): 60 at GC, 20 at PG and 2 at Pt. Such 
TABLE 2 -

Values calculated for $k$ for the reaction ${ }^{a}: \mathrm{NADH}^{+\cdot} \stackrel{k}{\rightarrow} \mathrm{NAD}+\mathrm{H}^{+}$

\begin{tabular}{|c|c|c|c|}
\hline Electrode & Background and buffer & pH & $k, s^{-i}$ \\
\hline$\overline{\text { GCE }^{6}}$ & $\begin{array}{l}0.25 \mathrm{M} \mathrm{Na}_{2} \mathrm{SO}_{4} \\
\text { or } 0.5 \mathrm{MCC} \text {; } \\
0.05 \mathrm{M} \text { Tris or } \\
\text { Phosphate }\end{array}$ & $6-10$ & $\begin{array}{l}60 \pm 30^{f, i} \\
60 \pm 30^{8.8}\end{array}$ \\
\hline $\mathrm{GCE}^{\mathrm{c}}$ & $\begin{array}{l}0.5 \mathrm{M} \mathrm{KCl} \\
0.5 \mathrm{MTris}\end{array}$ & 7 & $50 \pm 30^{h . J}$ \\
\hline $\mathrm{GCE}^{b}$ & $\begin{array}{l}0.1 \mathrm{MBu}_{4} \mathrm{NClO}_{4} \\
\text { in DMSO }\end{array}$ & & $\begin{array}{l}8 \pm 4^{f .5} \\
7 \pm 4^{83}\end{array}$ \\
\hline PGE & $\begin{array}{l}0.5 M \mathrm{KCl} \\
0.5 M \text { Tris }\end{array}$ & 7.1 & $20 \pm 10^{\text {s.k }}$ \\
\hline PE ${ }^{e}$ & $\begin{array}{l}0.5 M \mathrm{KCl} \\
0.005 M \text { Tris }\end{array}$ & 7.1 & $2 \pm 1^{f k}$ \\
\hline
\end{tabular}

a NADH concentration $=1 \mathrm{~m} M$. Data taken from Ref. 6.

b Stationary glassy carbon electrode covered with adsorbed NAD ${ }^{+}$.

- Rotating commercial electrode covered with adsorbed NAD ${ }^{+}$.

d Stationary pyrolytic graphite electrode covered with adsorbed NAD ${ }^{+}$.

- Stationary piatinum electrode without preparation or pretreatment.

$f$ Based on the sweep voltammetric relation $R T k=\beta \mathscr{F} U_{0}$ -

8 Eased on the chronoamperometric $I$ versus $t^{-1 / 2}$ curve

${ }^{h}$ Based on the effect of electrode rotation rate.

- Mean and standard deviation for 10 experiments.

1 Mean and standard deviation for 3 experiments.

* Mean and standard deviation for 5 experiments.

data support the notion of $\mathrm{NAD}^{+}$acting as a mediator in respect to electron and proton transfer during NADH oxidation, e.g., NADH exchanges the electron with an adsorbed $\mathrm{NAD}^{+}$which, in turn, exchanges the electron with the electrode.

Mechanism for unoccupted adsorption sites. Even on electrodes not covered with adsorbed $\mathrm{NAD}^{+}$, the initial step in the NADH oxidation proceeds to at least some extent through mediator redox systems located close to the electrode surface such as the redox couples formed by oxygen adsorbed at $\mathrm{Au}$ and $\mathrm{Pt}$ surfaces, e.g., $\mathrm{OH}_{a d s}^{*} / \mathrm{H}_{2} \mathrm{O}$ and $\mathrm{O}_{a d s} / \mathrm{OH}_{a d s}^{-}$and by organic functionalities resulting from oxidation of a carbon surface, e.g., quinone/semiquinone/hydroquinone systems [33]. Such an intimate involvement of surface oxygen species in the rate-determining step of overall reaction 10 was first suggested for the Pt electrode by Blaedel and Jenkins [26], who, however, rejected the hypothesis [33],

$\mathrm{NADH}+\mathrm{H}_{2} \mathrm{O} \rightarrow \mathrm{NAD}+\mathrm{H}_{3} \mathrm{O}^{+}+\mathrm{e}^{-}$

The possible involvement of two surface oxygen redox systems in the first stage of the NADH oxidation is schematically depicted in Fig. 6. The electron-transfer path 
involves electron exchange between energy levels located at the surface oxygen atom and in the electrode, coupled with electron exchange between energy levels of the surface oxygen atom and the solution NADH molecule. The proton transfer path

$\Delta$
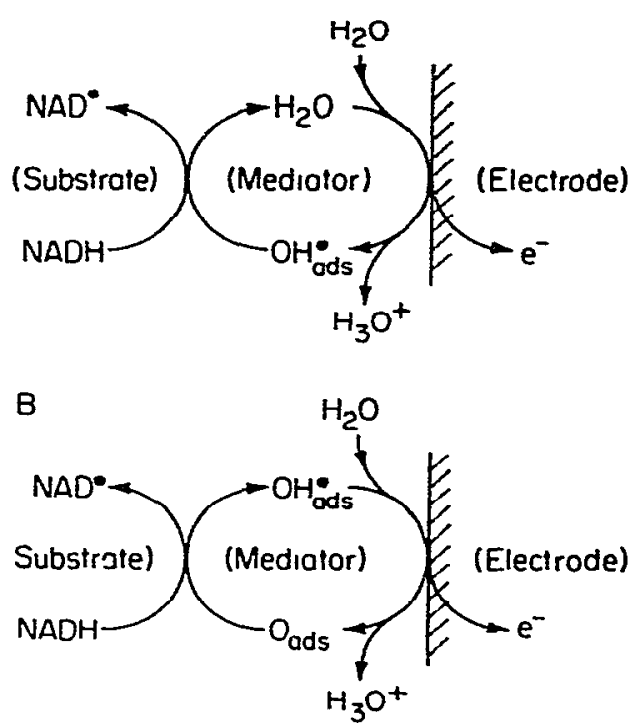

Fig. 6. Schematic representations of possible surface oxygen redox systems as mediators in the oxidation of NADH at soltd electrodes (A) $\mathrm{OH}_{a d s}^{\cdot} / \mathrm{H}_{2} \mathrm{O}$ redox couple. (B) $\mathrm{O}_{a d s} / \mathrm{OH}_{a d s}$ redox couple. (Taken from Ref. 33.)

(Fig. 7) involves transfer of the proton bound to C(4) of NADH to a third species, which is the proton acceptor, e.g., $\mathrm{H}_{2} \mathrm{O}$, with possible intermediate formation of a bond to the surface oxygen atom.

Thus, two mechanisms can be envisaged for the proton transfer path. In one, electron transfer through the intermediate state located close to the surface oxygen atom and proton transfer are decoupled from each other, i.e., the proton bound to $\mathrm{C}(4)$ of NADH is not involved in the activated complex formed before electron transfer may occur. The stable intermediate state in the electron transfer path, which

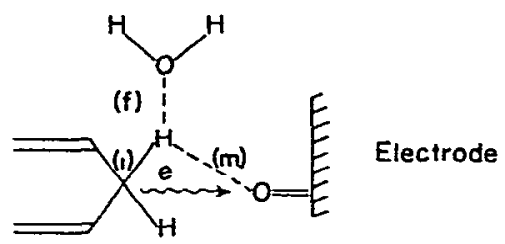

Fig 7. Proton transfer path on oxidation of NADH involving movement of $H$ from $C(4)$ of the nicotinamide ring to a proton acceptor such as $\mathrm{H}_{2} \mathrm{O}$, where $(1),(f)$ and $(m)$ designate the initual, final and possible intermediate bonds, respectively, of the iransferred proton. 
may be but need not be actually formed, would be represented by $\mathrm{NADH}^{+-}$and $\mathrm{O}_{a d s}\left(\mathrm{OH}_{a d s}^{+}\right)$Subsequently, the proton is transferred from $\mathrm{NADH}^{+}$to a proton acceptor in a distinct chemical step, which would be the reverse of steps in equation 4 and which is supported by a variety of data, e.g., Ref. 6 .

In the second mechanism, a bond is formed between the transferred proton and the surface atoms, and the intermediate state in the electron-transfer path would be represented by $\mathrm{NAD}^{-}$and $\mathrm{OH}_{a d s}^{*}\left(\mathrm{H}_{2} \mathrm{O}\right)$. In order that the inner-bridge activated complex be formed, reorganization of the proton configuration with respect to both $C(4)$ and surface oxygen atoms and proton acceptor (cf. Fig. 7) is necessary.

On the whole, irrespective of whether or not a stable intermediate state is actually formed, electron transfer through a mediator energy level may represent a path which is kinetically more favorable than direct electron transfer.

Analogous catalysis of NADH oxidation is provided by sulfide species adsorbed on a gold surface [33] and, as noted, by $\mathrm{NAD}^{+}$adsorbed on a carbon surface. Such catalysis via mediator redox couples is probably fairly common, e.g., for chioride ion adsorbed on platinum electrodes and for chemically modified electrode surfaces.

Although the enzymatically mediated oxidation of NADH has been generally considered to proceed by a single step involving hydride ion transfer, mechanisms based on two $1 \mathrm{e}^{-}$steps with intermediate $\mathrm{NAD}^{-}$formation have been considered, e.g., Refs. 15 and 34 to 37.

\section{ACKNOWLEDGMENT}

The authors thank the National Science Foundation which helped support the work described.

\section{REFERENCES}

1 A.L. Underwood and R.W. Burnett in Electroanalytical Chemistry, A.J. Bard, Editor, Marcel Dekker, New York, 1973, Vol. 6, Ch. 1.

2 P.J. Elving, C.O. Schmakel and K.S.V. Santhanam, Crit. Rev. Anal. Chem., 6 (1976) 1.

3. P.J. Elving, in Topics in Bioelectrochemistry and Bioenergetics, G. Milazzo (Editor), Wiley-Interscience, 1976, Vol.1, p. 278.

4 G. Dryhurst, Electrochemistry of Biological Molecules, Academic Press, New York, 1977.

5 R.L. McCreery, Crit. Rev. Anal. Chem., 7 (1978) 89.

6 J. Moiroux and P.J. EJving, J. Am. Chem. Soc., 102 (1980) 6533.

7 W.T. Bresnahan and P.J. Elving, J. Am. Chem. Soc., 103 (1981) 2379.

8 W.T. Bresnahan and P.J. Elving. Biochim. Biophys. Acta, 678 (1981) 151.

9 R.H. Sarma and R.J. Mynott, J. Am. Chem. Soc., 95 (1973) 7470.

10 W.D. Hamill, R.J. Pugmire and D.M. Grant, J. Am. Chem. Soc., 96 (1974) 2885.

I1 D. Perahia, B. Pullman and A. Saran in Structure and Conformation of Nucleic Acids and Protein-Nucleic Acid Interactions, M. Sundaralingam and S.T. Rao, (Editors), University Park Press, Baltimore, 1975, p. 685 .

12 C.O. Schmakel, K.S.V. Santhanam and P.J. Elving, J. Am. Chem. Soc., 97 (1975) 5083.

13 C.O. Schmakel, Ph.D. Thesis, University of Michigan, Ann Arbor, Mi, 1971.

14 K.S.V. Santhanam arid P.J. Elving, J. Am. Chem. Soc., 95 (1973) 5482.

I5 E.M: Kosower, A. Teuerstein, H.D. Burrows and A.J. Swallow, J. Am. Chem. Soc., 100 (1978) 5185. 
16 Y. Ohnishi, Y. Kikuchı and M. Kitami. Tetrahedron Lett., 32 (1979) 3005.

17 M.A. Jensen, Ph.D. Thesıs, The University of Michigan, Ann Arbor, MI, 1977.

18 W.T. Bresnahan, J Moiroux, Z. Samec and P.J. Elving, Bioelectrochem. Bioenerg., 7 (1980) 125.

19 C P.K. Preciston Molecular Models, The Ealing Corporation, 2225 Massachusetts Ave., Cambridge, MA 02140, U.S A.

20 H. Sund in Bıological Oxidatıons. T.P. Singer (Editor), Interscience, New York, 1958, p. 603.

21 E.J. Lund and A.J. Swallow, Biochim. Biophys Acta, 162 (1968) 327.

22 J. Motroux and P.J. Elving. J. Electroanal. Chem., 102 (1979) 93.

23 J. Moiroux and P.J. Elving. Anal. Chem, 50 (1978) 1056.

24 J. Moiroux and P.J. Elving. Anal. Chem, 51 (1979) 346.

25 R.D. Braun, K S.V. Santhanam and P.J. Elving. J. Am. Chem. Soc, 97 (1975) 2591.

26 W J. Blaedel and R A. Jenkins, Anal. Chem., 47 (1975) 1337.

27 P. Leduc and D Thévenot. Bıelectrochem Bioenerg . I (1974) 96.

28 P. Leduc and D. Thévenot, J Electroanal. Chem., 47 (1973) 543.

29 R.W Coughin and B.F. Alexander, Biotech. Broeng . 17 (1975) 1379.

30 D. Chi-Sing Tse and T. Kuwana. Anal. Chem., 50 (1978) 1315.

31 L. Nadjo and J M. Savéant. J. Electroanal Chem., 33 (197i) 419

32 L. Nadjo and J.M. Saveant, J. Electroanal. Chem, 48 (1973) 113.

$33 \mathrm{Z}$ Samec and P.J. Elving. in preparatıon.

34 B H Bielskı and P.C Chan, J Am Chem. Soc. 102 (1980) 1713.

35 E.M. Kosower, Prog Phys. Org. Chem, 3 (1965) 81.

36 E.M. Kosower in Free Radicals in Biology, W. Pryor (Editor), Academic Press, New York, 1976, Vol. II. Ch 1.

37 T.C. Bruice, Ann. Rev. Biochem , 45 (1976) 331 